\title{
Optoelectronics education training programs in Scotland
}

John Marsh

John H. Marsh, "Optoelectronics education training programs in Scotland," Proc. SPIE 4588, Seventh International Conference on Education and

Training in Optics and Photonics, (28 May 2002); doi: 10.1117/12.468721

SPIE Event: Education and Training in Optics and Photonics 2001, 2001, Singapore, Singapore 
Invited Paper

\title{
Optoelectronics Education and Training Programmes in Scotland
}

\author{
John H. Marsh \\ Chief Research Officer \\ Intense Photonics Ltd, \\ 4 Stanley Boulevard, Hamilton International Technology Park, \\ High Blantyre G72 0UX, Scotland, UK \\ john_marsh@intensephotonics.com
}

\begin{abstract}
The optoelectronics industry is of increasing importance to the Scottish economy, with annual sales of \$1 billion and it is planned to grow this to $\$ 8.8$ billion by 2010 . The industry already employs around 5,000 people and, in the last year, 800 new jobs were created, including a high percentage filled by graduates and $\mathrm{PhDs}$. One of the major challenges is to provide staff training at all levels: technicians, graduates and postgraduates. A variety of organisations - industry, government, university and professional societies - are working together to meet his challenge.
\end{abstract}

\section{INTRODUCTION}

Scotland has a well-developed high-technology and service industry economy. The electronics industry is Scotland's largest, with 41,000 direct employees and annual sales of $\$ 32$ billion (Table 1). This represents the largest concentration of semiconductor manufacturing anywhere in Europe, accounting for 13\% of the total European production capacity. The related optoelectronics industry is recognised as being of increasing importance, and already has 5000 direct employees and annual sales of $\$ 1$ billion. Of these sales, $60 \%$ are exported and $99 \%$ are own-company products.

World-wide growth in optoelectronics is driven largely by data communications, and the current exponential growth in internet traffic. As a result, it is predicted that the demand for increased communications bandwidth will grow by a factor of 300 within the next 10 years. Other areas with high growth potential in optoelectronics include displays, biotechnology and medicine. Scottish universities have been particularly active in optoelectronics research, and are now being actively encouraged by government to transfer successful research projects into industry, in many instances via start-up companies.

The growth potential of optoelectronics has been recognised by the economic development agency, Scottish Enterprise (SE). Optoelectronics has been selected by SE as a core industry to help in the country's economic growth. Its inclusion as a 'New Wave Cluster' means it will receive focused government resources. Turnover targets of $\$ 2.6$ billion in 2005 and $\$ 8.8$ billion in 2010 have been set. The industry currently employs around 5,000 people and, in 2000, 800 new jobs were created, including a high percentage requiring graduates and $\mathrm{PhDs}$. Key data concerning the sector are given in Table 2. The industry requires specially trained staff at all levels - technicians, graduates and postgraduates - and, to meet this need, industry, government, university and professional societies are working together.

\begin{tabular}{|l|l|}
\hline ales & $\$ 32$ billion, \\
\hline irect employees & 41,000 \\
\hline uropean semiconductor capacity & $15 \%$ \\
\hline uropean PC \& notebook production & $30 \%$ \\
\hline orld PC production & $7 \%$ \\
\hline uropean ATM manufacture & $65 \%$ \\
\hline omputer manufacturers & $\begin{array}{l}3 \text { of top 5 major companies (Sun, IBM \& } \\
\text { Compaq) }\end{array}$ \\
\hline elecom equipment manufacturers & $\begin{array}{l}\text { Major companies (Agilent, Alcatel, NEC \& } \\
\text { Motorola) }\end{array}$ \\
\hline
\end{tabular}

Table 1. Scottish electronics sector - key data. 


\begin{tabular}{|l|l|}
\hline Sales in 1999 & $\$ 1 \mathrm{~b}$ \\
\hline Direct employees & 5000 \\
\hline Exports & $60 \%$ \\
\hline Universities engaged in Optoelectronics research & 12 out of 13 \\
\hline Researchers & 350 \\
\hline
\end{tabular}

Table 2. Scottish optoelectronics sector - key data.

\section{UNIVERSITIES}

Scotland is home to 16 separate departments in 12 universities with some specialisation in optoelectronics (Fig. 1), and together these departments employ more than 350 researchers. Many groups are internationally recognised as holding a position of excellence in optoelectronics technology, continuing a long tradition of inventive genius in science and engineering. Since the early $19^{\text {th }}$ century, many Scottish innovations have made vital contributions to the development of modern technology and civilisation. Those of James Clerk Maxwell and William Thompson (Lord Kelvin) are outstanding. Other examples include James Watt's improved steam engines that forced the pace of the European industrial revolution; Alexander Graham Bell's telephone that ushered in a new age in telecommunications; John Logie Baird's television that changed forever how we see the world. As early as 1844, Alexander Bain devised facsimile transmission, his Automatic Chemical Recording Telegraph leading directly to the modern fax machine.

Scottish universities account for around half of all United Kingdom graduates in optoelectronics (details in Table 3). Degree courses are constantly being developed and, each year, an estimated 550 students graduate with some exposure to optoelectronics. Most taught courses offer specific optoelectronics modules within general electronic engineering and physics degree programmes. There are, however several dedicated courses including the following

- $\quad$ BSc in Electronics \& Photonics (Dundee \& St. Andrews)

- $\quad$ MSc in Photonics \& Optoelectronics (St. Andrews \& Heriot-Watt)

- $\quad \mathrm{MSc}$ in Displays Technologies (CUPID)

- $\quad$ MSc course with optoelectronics modules (Glasgow).

The CUPID (Combined University Partnership with Industry in Displays) Consortium has been formed by Abertay, Edinburgh, Heriot-Watt, Napier and Dundee Universities. Its facilities include space for company incubation, a research 'hotel' and packaging, all backed up by extensive capital equipment. As indicated above, the consortium offers an MSc Degree, and this is built from packages in Display Technology and Micro-engineering. Uniquely, it offers education and training programmes at all levels from technician National Certificate through to Masters Degree.

\begin{tabular}{|l|l|}
\hline Specialist undergraduate degree courses & $\begin{array}{l}\text { New initiative: Optoelectronics/Electronics (St } \\
\text { Andrews/Dundee) }\end{array}$ \\
\hline MSc Degrees in Optoelectronics & $\begin{array}{l}\text { Heriot-Watt/St Andrews: new Masters Training } \\
\text { Packages }>£ 1 m \text { for 5 years } \\
\text { MSc in Displays Technologies (CUPID) }\end{array}$ \\
\hline PhD Degree Projects & $\begin{array}{l}\text { Laser/Optoelectronics/Photonics/Tele/Data- } \\
\text { Comms } \\
\text { Engineering Doctorate Centre for Photonics } \\
\text { Engineering (Heriot-Watt, Strathclyde \& St. } \\
\text { Andrews) }\end{array}$ \\
\hline Research Facilities & State-of-the-art \\
\hline Industrial R\&D groups & Excellent collaborations \\
\hline
\end{tabular}

Table 3. University sector education and training in optoelectronics. 

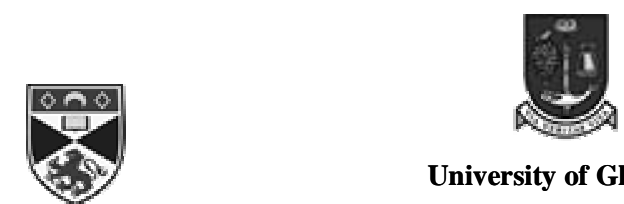

University of Glasgow

University of St Andrews
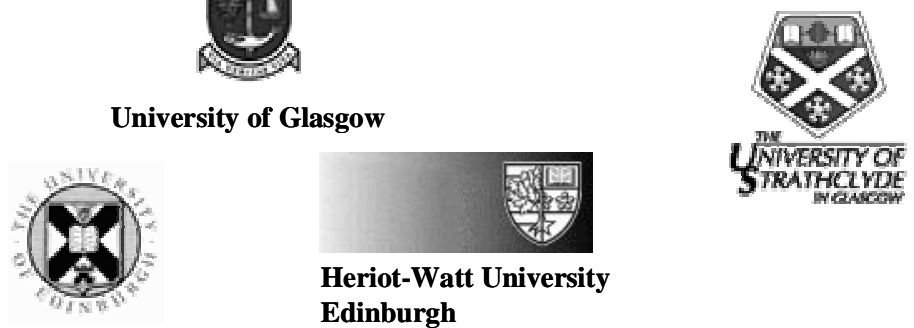

\section{Heriot-Watt University \\ Edinburgh}
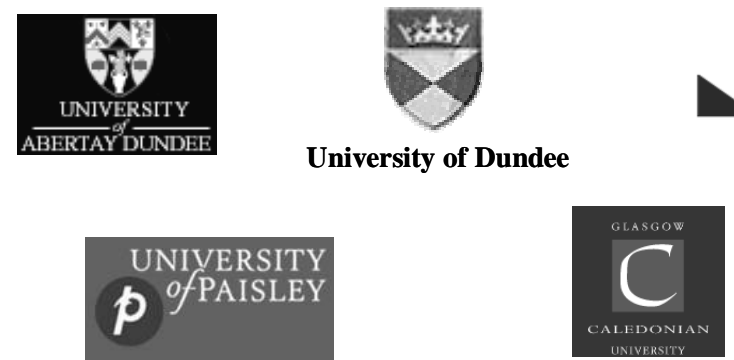

NAPIER

UNIVERSITY

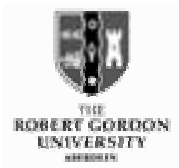

University of Dundee

WNINERSII

Figure 1. Scottish universities active in optoelectronics

Universities with large research programmes include Edinburgh, Glasgow, Heriot-Watt, St Andrews and Strathclyde, with significant activity elsewhere. It has been estimated that Scottish Universities win approximately $50 \%$ of all UK public research funding in optoelectronics, against a population that is only a tenth of the UK total. Areas of notable strength include

- Semiconductor materials

- Optoelectronic devices

- Photonic integrated circuits

- Optical information processing

- Diode pumped solid state lasers

- Carbon dioxide lasers

- Optical computing

- Optical sensors

- Semiconductor lasers

- Optical component performance monitoring

Projects are staffed by higher degree students and post-doctoral researchers. Research students usually graduate with the degree of $\mathrm{PhD}$, and post-doctoral training is supported via fixed-term 'research assistant' posts. The UK Engineering and Physics Research Council is responsible for funding many of these posts.

Several universities have established separate institutes or companies to support collaboration with industry. These include

- Kelvin Nanotechnology Ltd (University of Glasgow)

- Institute of Photonics (University of Strathclyde)

- Photonics Innovation Centre (University of St Andrews)

- $\quad$ EPI Centre (University of Abertay) 


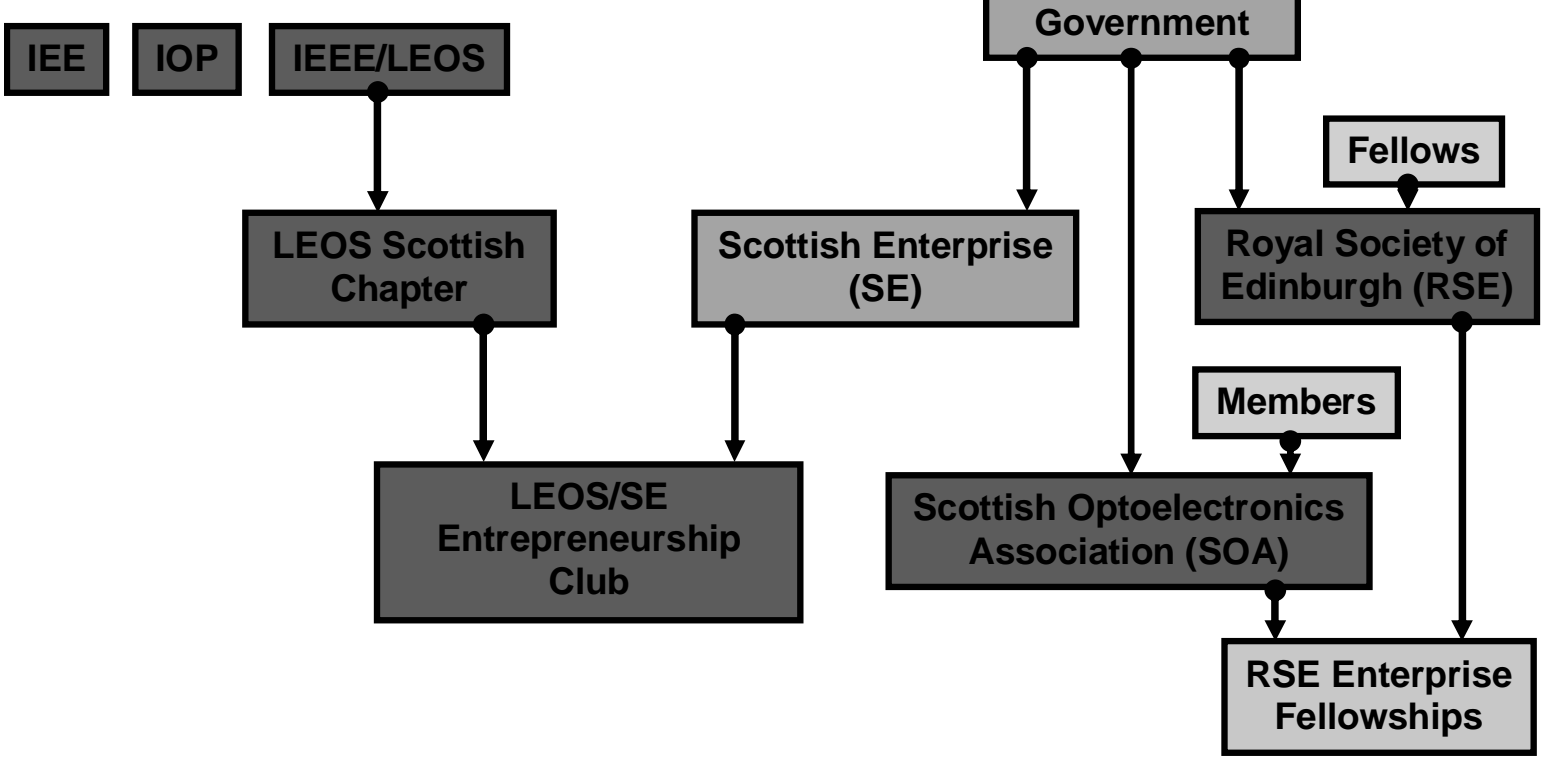

Figure 2. Photonics-related professional societies in Scotland.

\section{PROFESSIONAL BODIES}

Against this background, several professional bodies are making significant contributions (Fig. 2). All professional societies and universities are aware of the need for outreach to the general public, and to young people in particular, and have well-established programmes in place. The Institution of Electrical Engineers (IEE) and the Institute of Physics (IOP) both organise technical meetings on a UK basis, many of which are held in Scotland. Sector specific training is offered by these organisations through summer schools. In addition there are activities specifically developed within Scotland.

\subsection{SCOTTISH OPTOELECTRONICS ASSOCIATION}

The Scottish Optoelectronics Association (SOA) was established in 1994 to represent the optoelectronics community in Scotland and has strong links with similar bodies world-wide. Its aims are to

- Act as a focus for the optoelectronics community between and within both industry and academia.

- Collect, assimilate and disseminate knowledge and information of benefit to the optoelectronics industry in Scotland.

- Promote the growth of optoelectronics businesses by the provision of support in international marketing, elucidating the case for support of relevant research and development and improving the interface with the financial community and government agencies.

- $\quad$ Provide assistance and support to users of optoelectronics in Scotland.

In the context of training, the SOA works closely with the Scottish Enterprise (SE) network to identify particular skills shortages. At present a 'skills strategy' is being developed across the electronics, microelectronics, optoelectronics and telecommunications sectors to define the technical requirements of industry and couple this with university resources. SOA and SE offer schemes to address specific training needs, which may be centred around one particular company, 


\begin{tabular}{|l|l|}
\hline $8-12$ meetings per annum & $\begin{array}{l}\text { Outstanding keynote speakers } \\
\text { LEOS Distinguished Lecturer Program } \\
\text { Student/post-doc sessions }\end{array}$ \\
\hline $\begin{array}{l}\text { Entrepreneurship Club joint with Scottish } \\
\text { Enterprise }\end{array}$ & $\begin{array}{l}\text { Technical, financial, industrial and commercial } \\
\text { advice } \\
\text { Dedicated web site restricted to members }\end{array}$ \\
\hline Half-day meeting format & $\begin{array}{l}\text { Rotating venue } \\
\text { Commercial sponsorship of meetings } \\
\text { Social event with posters }\end{array}$ \\
\hline Collaboration with other bodies & Including IEE, IOP, SOA, SE, SUSSP \\
\hline
\end{tabular}

Table 4. IEEE/LEOS Scottish Chapter - Key Activities \& Features.

but not exclusive to that company. The SOA can help to support recruitment at graduate level from outside Scotland when particular skills shortages are identified.

\subsection{SCOTTISH CHAPTER OF IEEE/LASERS AND ELECTRO-OPTICS SOCIETY}

The Scottish Chapter of the IEEE Lasers and Electro-Optics Society (LEOS) was established in February 1996. It has been highly active and successful: in 1997, 1998 and 2000 it was winner of the LEOS Chapter-of-the-Year Award and in 1999 Most Innovative Chapter Award. It activities are summarised in Table 4. Most meetings have an innovative half-day format that combines talks given by prestige speakers, with student/post-doc presentations, posters and a social event. Meetings are intended to be sufficiently substantial to make it worth travelling across the Scottish central belt to the meeting venue, yet sufficiently short to allow there-and-back travel in a day. Extensive use is made of the LEOS Distinguished Lecturer Programme, and almost all distinguished lecturers appointed since 1996 have spoken at Chapter meetings.

As well as offering a forum for education and networking, one of its major activities has been to establish an 'Entrepreneurship Club' with Scottish Enterprise. The club is open to anyone interested in commercialising ideas in optoelectronics. It holds regular meetings ( 2 to 4 per annum) and its advisers are drawn from entrepreneurs, angels, banks, venture capital houses and government advisors. On average, the last few years have seen eight new start-up companies per annum, and some of the help and inspiration for this has come from the Entrepreneurship Club.
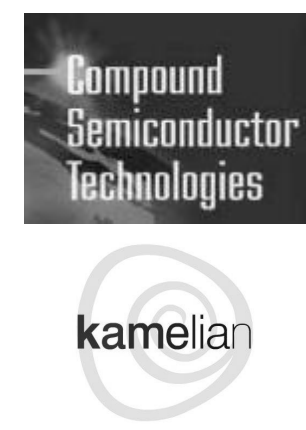

\section{Lifor Ltd}
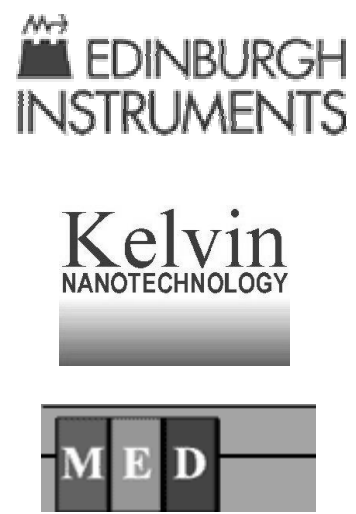

intensephotonics

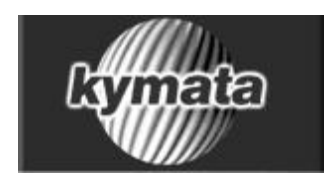

Terahertz photonics

Figure 3: Examples of recent start-up companies. 


\subsection{ROYAL SOCIETY OF EDINBURGH}

The Royal Society of Edinburgh (RSE) is Scotland's 'National Academy', with around 1200 Fellows drawn from all disciplines. It supports and administrates a range of conventional research fellowships, several of which are awarded in optoelectronics in a given year. These fellowships support individual research in a University, usually for 3 years. In addition it offers 'Enterprise Fellowships' in optoelectronics funded by Scottish Enterprise. The Fellowships provide financial support and business training for one year in order to bring forward concepts for commercialisation. Several recent start-up companies have received such support.

\section{CONCLUSION}

The success of this multi-facetted strategy is beginning to bear fruit. On average, eight new Scottish optoelectronics start-up companies emanate from either the optoelectronics research base or established firms each year (for some examples see Fig.3). Last year new start-ups attracted $£ 85$ million investment and indigenous companies are beginning to establish themselves as global players. Professional bodies are an important component in enabling such growth.

\section{ACKNOWLEDGEMENTS}

John H. Marsh is Professor of Optoelectronic Systems in the University of Glasgow. He is currently seconded to Intense Photonics Ltd. 